19 Revue d'histoire du XIXe siècle

Société d'histoire de la révolution de 1848 et des

révolutions du XIXe siècle

$37 \mid 2008$

L'ère victorienne revisitée

\title{
Jules MICHELET, Histoire de France, choix de textes présentés par Paule Petitier
}

Jean-Claude Caron

\section{OpenEdition}

\section{Journals}

Édition électronique

URL : http://journals.openedition.org/rh19/3528

DOI : $10.4000 /$ rh 19.3528

ISSN : $1777-5329$

Éditeur

La Société de 1848

Édition imprimée

Date de publication : 15 novembre 2008

Pagination : 185-242

ISSN : 1265-1354

Référence électronique

Jean-Claude Caron, « Jules MICHELET, Histoire de France, choix de textes présentés par Paule Petitier », Revue d'histoire du XIXe siècle [En ligne], 37 | 2008, mis en ligne le 01 décembre 2008, consulté le 22 septembre 2020. URL : http://journals.openedition.org/rh19/3528 ; DOI : https:// doi.org/10.4000/rh19.3528

Ce document a été généré automatiquement le 22 septembre 2020

Tous droits réservés 


\title{
Jules MICHELET, Histoire de France, choix de textes présentés par Paule Petitier
}

\author{
Jean-Claude Caron
}

\section{RÉFÉRENCE}

Jules MICHELET, Histoire de France, choix de textes présentés par Paule Petitier, Paris, Flammarion, 2008, 533 p. ISBN : 978-2-08-120479-9. 22 euros.

Jules MICHELET, Histoire de France. I. La Gaule. Les Invasions. Charlemagne. II. Tableau de la France. Les Croisades. Saint Louis, édition présentée par Paul Viallaneix et Paule Petitier, Sainte-Marguerite-sur-Mer, Éditions des Équateurs, 2008, 2 volumes, 461 et 522 p. ISBN : 978-2-84990-071-0 et 978-2-84990-072-7. 15 euros le volume.

1 Aucun de ces trois volumes ne parle du XIX ${ }^{\mathrm{e}}$ siècle et pourtant tous y sont étroitement reliés par leur auteur et par leur objet. Il faut saluer comme un événement la réédition de l'intégralité de l'Histoire de France de Michelet, dans un format facile à manier. Depuis l'édition des Euvres complètes par Gabriel Monod à la fin du XIX ${ }^{\mathrm{e}}$ siècle, nul éditeur ne s'y était risqué. Ni la collection "Bouquins", ni les CEuvres complètes publiées chez Flammarion n'ont proposé cette intégralité. Lacune majeure pour ce « saint Patron » de l'histoire qui n'ambitionnait rien moins que la résurrection intégrale du passé... Les dix-sept volumes prévus couvrent la totalité de cette histoire, des origines au règne de Louis XVI, y compris les «Éclaircissements » et l'« Appendice » qui fournissent à la fois l'administration de la preuve, un ensemble de citations, des commentaires : on y voit Michelet à l'œuvre, en quelque sorte, dans ces textes où le ton autobiographique se fait parfois entendre. On saluera de prime abord la double introduction de Paul Viallaneix et de Paule Petitier, qui se complètent pour mettre en perspective la portée de l'œuvre de Michelet - avec un émouvant rappel autobiographique dans le cas de Paul Viallaneix. Et on rappellera la présence, dans le deuxième volume, du célèbre « Tableau 
de la France ", qui constitue en lui-même une partie autonome (et déjà rééditée en tant que tel) tout en donnant la clef de la philosophie micheletienne de l'histoire.

2 La lecture d'une histoire à la fois savante, psychologique, romancée, engagée produit un double sentiment sur le lecteur actuel, en particulier lorsqu'il se dit historien : celui d'un éloignement difficile à combler avec une écriture de l'histoire qui n'est plus, ne peut plus être de mise; mais aussi celui d'une liberté perdue. Histoire téléologique, intentionnelle, au service d'une cause, certes ; mais un mélange rare de démonstration fondée sur le document d'archive - qui va dès lors entreprendre sa marche vers la sacralisation - et d'intuition bienvenue. Remarquable apparait en particulier l'articulation entre des trajectoires individuelles et des mouvements collectifs. Remarquable aussi, au delà de la maîtrise d'un savoir encyclopédique, la restitution de celui-ci dans une langue claire et accessible. Remarquable, enfin, l'articulation entre le présent de l'écriture - qui est aussi histoire : on sait comment Michelet date de la Révolution de 1830 l'origine de son projet - et le passé de l'objet: deux dimensions temporelles indissociables, car, comme le rappelle Paule Petitier, pour Michelet, " écrire l'histoire, c'est la faire ».

Dire de cette Histoire de France qu'elle se lit comme un roman apparait comme un crime de lèse-majesté. Or, dans l'introduction au choix de textes qu'elle a sélectionnés, Paule Petitier n'hésite pas à comparer l'œuvre monumentale de Michelet à des monuments littéraires qui partagent avec celle de l'historien l'ambition de constituer une œuvre totale ou une œuvre-monde : La Comédie humaine, Les Rougon-Macquart, À la recherche du temps perdu. L'invitation est tentante et la lecture de l'Histoire de France au prisme de Proust, de Balzac et de Zola ne manque pas d'arguments. Le côté Proust pour le souci commun d'" épopée de la mémoire ", de réminiscence, de présence du moi ; le côté Balzac pour cette retranscription, sur un autre mode certes, d'une comédie humaine à travers les siècles, mais aussi pour ce morceau de littérature panoramique, pour le recours au spirituel, au psychologique, pour la révélation de ce qui n'était pas visible, par le recours conscient à la dramatisation; le côté Zola, enfin, pour l'idée de cycle, captée chez Vico, adaptée à l'histoire de la nation France vue au travers d'un « imaginaire vitaliste et organique ».

Histoire de France ? Certes, mais, lorsque le besoin s'en fait sentir, Michelet élargit la perspective à une dimension européenne, voire mondiale. Histoire des grands hommes? Certes, mais aussi du peuple, dont Michelet se flatte d'être issu, lui le «barbare», et dont il dit la fierté d'être le premier à en faire, dès le début chronologique de cette œuvre, un acteur de l'histoire. Les femmes ne sont pas absentes de cette histoire. Elles y occupent une place comme dans aucune autre Histoire de France, pendant longtemps. Croyances, sociabilité, sensibilités, symboles, arts, alimentation, goût, vêtements, musique, rien n'échappe aux sens en éveil de Michelet. Là réside une modernité qui subsiste encore dans cette œuvre qui appartient pourtant à l'historiographie. Qu'on la lise dans son intégralité (à ce jour, les cinq premiers tomes sont parus) ou dans le choix de textes proposés ici, l'Histoire de France de Michelet demeure une irremplaçable leçon d'ambition et de modestie. 